\title{
Immune responses in COVID-19 and potential vaccines: Lessons learned from SARS and MERS epidemic
}

\author{
Eakachai Prompetchara, ${ }^{1,2,3}$ Chutitorn Ketloy, ${ }^{1,2}$ Tanapat Palaga ${ }^{4,5}$
}

\begin{abstract}
As the world is witnessing the epidemic of COVID-19, a disease caused by a novel coronavirus, SARS-CoV-2, emerging genetics and clinical evidences suggest a similar path to those of SARS and MERS. The rapid genomic sequencing and open access data, together with advanced vaccine technology, are expected to give us more knowledge on the pathogen itself, including the host immune response as well as the plan for therapeutic vaccines in the near future. This review aims to provide a comparative view among SARS-CoV, MERS-CoV and the newly epidemic SARS-CoV-2, in the hope to gain a better understanding of the host-pathogen interaction, host immune responses, and the pathogen immune evasion strategies. This predictive view may help in designing an immune intervention or preventive vaccine for COVID-19 in the near future.
\end{abstract}

Key words: Coronavirus, immune response, COVID-19, immune evasion, immunopathology

From:

${ }^{1}$ Center of Excellence in Vaccine Research and Development

(Chula Vaccine Research Center Chula VRC), Faculty of Medicine, Chulalongkorn University, Bangkok 10330, Thailand

2 Department of Laboratory Medicine, Faculty of Medicine, Chulalongkorn University, Bangkok 10330, Thailand

3 Vaccines and Therapeutic Proteins Research Group, the Special Task Force for Activating Research (STAR), Chulalongkorn University, Bangkok 10330, Thailand

${ }^{4}$ Department of Microbiology, Faculty of Science,

Chulalongkorn University, Bangkok 10330, Thailand

${ }^{5}$ Center of Excellence in Immunology and Immune-mediated Diseases, Chulalongkorn University, Bangkok 10330, Thailand

\section{Introduction}

The world experienced the outbreaks of coronavirus infection that threaten global pandemic in 2002-2003 by Severe Acute Respiratory Syndrome (SARS) and in 2011 by Middle East Respiratory Syndrome (MERS). In both cases, the causative agents (SARS-CoV and MERS-CoV, respectively) were newly identified coronavirus in the genus Betacoronavirus with zoonotic origin. At the end of 2019, outbreak of another coronavirus that causes respiratory-related illness was reported in Wuhan, Hubei, China, a disease now officially called "the Corona Virus Disease 2019; COVID-19”. The coronavirus that is the causative agent of this respiratory disease was identified and its genome is fully sequenced. ${ }^{1}$ The genomic sequence of SARS-CoV-2 showed similar, but distinct genome composition of SARS-CoV and MERS-CoV. Since its first reported case in late 2019, the infection has spread to other regions in China and other countries, and the transmission rate, the mortality rate and the clinical manifestation slowly emerged. However, it will take months and maybe years until we will fully grasp the whole picture of the characteristics of the pathogens and

\section{Corresponding author:}

Tanapat Palaga

E-mail: tanapat.p@chula.ac.th

its likely origin, symptoms and the host immune responses to combat the infection.

With the rapid bedside-to-bench investigation, newly available tools such as next generation sequencing (NGS) and the open access information, key information on the clinical features of the infected patients and the host immune responses started to accumulate for reconstructing the jigsaw puzzle of the epidemic piece by piece. $^{2}$ With its genome closely related to SARS-CoV and MERS-CoV and the accumulated clinical and experimental data on these previous viruses, one can hypothesize and even predict how the host immune system may deal with this particular virus and how the virus may evade such host responses. This review focuses on the immunology side of the infection using insights learned from the outbreak of SARS-CoV and MERS-CoV. Based on the accumulated data and knowledge on the previous coronavirus infection, this review hopes to fill the knowledge gap on human immune response to SARS-CoV-2 infection that may shed light on what may go wrong that leads to some fatalities. 
This insight may help in designing the appropriate immune intervention for treatment and the prophylactic/therapeutic vaccines against current coronavirus.

\section{Host-Pathogen Interaction: Emerging Profiles of SARS-CoV-2 Infection}

Investigation of emerging pattern or transmission characteristic of SAR-CoV-2 has surged after a burst of confirmed cases worldwide since December 2019. One of the initial reports stated that most of the laboratory-confirmed infected patients (27 out of 41 cases) had links to Wuhan seafood market. $^{2}$ Identification of the source or intermediate host of SARCoV-2 were attempted, focusing on animals normally traded within the market including snakes, birds and other small mammals. However, to date, no specific animal association with SAR-CoV-2 has been conclusively identified. The most likely intermediate host candidate is thought to be pangolins as the coronavirus genetic sequences from the animals and from humans infected during the outbreak showed a 99\% match, which was reported by the researchers at a press conference on February 7, 2020. ${ }^{3}$

In parallel with intermediate host identification, a study in one family revealed that 6 patients who had travelled to $\mathrm{Wu}$ han, had no direct contact with the market. Moreover, one of the family members became infected even without a trip to Wuhan. The conclusion was that SAR-CoV-2 could be transmitted from human-to-human, via respiratory droplets or close contact. ${ }^{4}$ A larger study with 425 patients also confirmed human-to-human transmission in which most of the patients (200 out of 277) who were diagnosed during January 1-22, 2020, had never been exposed to either the Wuhan market or been in close contact with individuals with respiratory symptoms. ${ }^{5}$

According to the rapid spreading of SAR-CoV-2, WHO issued a public health emergency of international concern (PHEIC) alarm on January 30, 2020. As of February 20, 2020, a total of 75,725 confirmed cases were reported in at least 29 countries worldwide with the fatality rate of $2.8 \%$ (2,126 out of
75,282 cases). ${ }^{6}$ Although the fatality rate is far lower than that of SARS $(9.14 \%)^{7}$ and MERS $(34.4 \%),{ }^{8}$ the accumulated confirmed cases, within approximately 2 months after the outbreak, markedly exceeded SARS, (8,096 cases, since 2002) and MERS (2,494 cases, since 2012), see Figure 1. The highly contagious nature of SAR-CoV-2 is probably due to the virus spreading via asymptomatic-infected individual which has been reported in Germany. ${ }^{9}$ Moreover, mathematical models have estimated that the transmission that may occur during asymptomatic period of SARS-CoV and influenza were approximately $5 \%$ and $40 \%$, respectively. ${ }^{10}$ Observation of 88 cases diagnosed during January 20-28, 2020 from individuals with travel history to Wuhan, found that the mean incubation period ranged from 2.1 to 11.1 days $($ mean $=6.4$ days), ${ }^{11}$ which is similar to another study ${ }^{5}$ and was in the same range with SARS-CoV and MERS-CoV. ${ }^{11}$ Longer incubation periods of up to 24 days was also reported ${ }^{12}$ but still under debate. WHO experts discussed during its press conference on February 10, 2020 that 24 days reported was either an outlier observation or could possibly be due to double exposure. ${ }^{13}$

Identification of SARS-CoV-2 tropism is also warranted. In agreement with genome similarity with SARS, analysis of nucleic acid sequence within the spike protein receptor-binding domain (RBD) has been predicted that SAR-CoV-2 might also use angiotensin-converting enzyme 2 (ACE2) as a cell receptor. $^{14}$ The study performed in vitro experiments which could confirm that SAR-CoV-2 used ACE2 for cellular entry. ${ }^{15}$ Because wild range of animal species (except rat and mouse) express ACE2, it could support the observed cross-species and human-to-human transmission events. Demographic data and emerging characteristic of SARS-CoV, MERS-CoV and SARCoV-2 are summarized in Table 1.

As SAR-CoV-2 is a novel human-infecting pathogen, recent studies also attempted to define more accurate infection situation and to forecast the outbreak in the near future. By using a mathematical model to calculate the basic reproductive number, $R_{0}$, which is the average number of people that
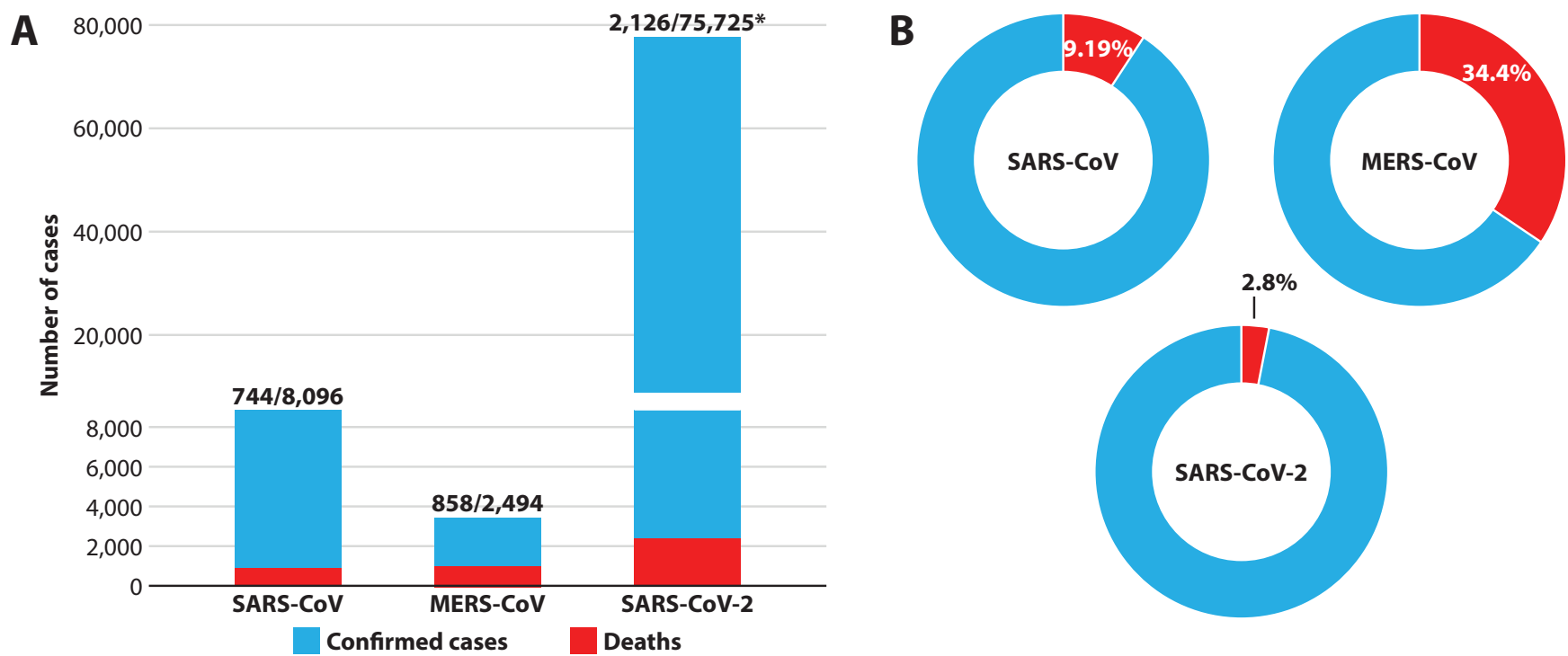

Figure 1. Comparative data of (A) deaths/total cases and (B) mortality rate of SAR-CoV, MERS-CoV and SARS-CoV-2. Numbers on bar graphs represent death/confirmed cases

${ }^{*}$ Data obtained Feb 20, 2020, 9.53 am. ${ }^{6}$ 
Table 1. Summary of demographic data and emerging characteristic of SARS-CoV, MERS-CoV and SAR-CoV-2

\begin{tabular}{|c|c|c|c|}
\hline & SARS-CoV & MERS-CoV & SARS-CoV-2 \\
\hline \multicolumn{4}{|l|}{ Demographic } \\
\hline Date/Place first detected & $\begin{array}{l}\text { November 2002/ } \\
\text { Guangdong China }\end{array}$ & $\begin{array}{c}\text { June, 2012/ } \\
\text { Jeddah, Saudi Arabia }\end{array}$ & $\begin{array}{l}\text { December, 2019/ } \\
\text { Wuhan, China }\end{array}$ \\
\hline Age, years (range) & $39.9(1$ to 91$)$ & $56(14$ to 94$)$ & $<1$ to $>80^{16,17}$ \\
\hline Confirmed cases & 8,096 & 2,494 & $75,725^{\star}$ \\
\hline Mortality rate & $744(9.19 \%)$ & $858(34.4 \%)$ & $2,126(2.8 \%)^{*}$ \\
\hline \multicolumn{4}{|l|}{ Host-Pathogen Interaction } \\
\hline Possible natural reservoir & Bat & Bat & Bat \\
\hline Possible intermediate host & Palm civets & Camel & Pangolin** \\
\hline Predominant cellular receptor & ACE2 & $\begin{array}{l}\text { Dipeptidyl peptidase } 4 \\
\text { (DPP4, also known as } \\
\text { CD26) }\end{array}$ & ACE2 \\
\hline \multicolumn{4}{|l|}{ Emerging characteristic } \\
\hline Number of affected country & 29 & 27 & $29^{*}$ \\
\hline Reproductive number, $R_{0}$ & $1.4-5.5$ & $<1$ & $2.2-2.6$ \\
\hline Epidemic doubling time & $\begin{array}{l}4.6 \text { to } 14.2 \text { days } \\
\text { (depending on } \\
\text { settings) })^{17}\end{array}$ & $90^{18}$ & $6.4^{15}$ \\
\hline
\end{tabular}

${ }^{\star}$ Obtained Feb 20, 2020, $9.53 \mathrm{am}^{6}$

${ }^{* *}$ Reported at press conference on February 7, $2020^{3}$

one infected individual will pass the virus on to. If $R_{0}$ is higher than 1, continued transmission can occur. $R_{0}$ of SAR-CoV-2 ranged from 2.2-2.6, with an epidemic doubling time of 6.4 days. ${ }^{5,18}$ This implies that, in order to reduce $R_{0}$ below 1 , more than half of the current infection must be prevented or controlled. ${ }^{19}$ Comparing with SARS-CoV and MERS-CoV which $R_{0}$ were $<1$ and 1.4-2.5, respectively, it implies that SAR-CoV-2 is more contagious than MERS-CoV and may cause an epidemic or even a pandemic if transmission is uncontrolled.

\section{Immunopathology of COVID-19}

The site of initial infection with SARS-CoV-2 is unknown and the pathogenesis of COVID-19 is still under investigation. For most patients, COVID-19 might affect only the lungs because it is mainly a respiratory disease. The primary mode of infection is human-to-human transmission through close contact, which occurs via spraying droplets from infected individual through their cough or sneeze. COVID-19 has a probable asymptomatic incubation period between 2 and 14 days during which the virus can be transmitted..$^{20}$ For this reason, the rapid spread of SARS-CoV-2 has occurred with the basic $R_{0}$ of 2.2-2.6, meaning that on average each individual has the potential to spread the infection to 2.2 other people. ${ }^{1,21}$

Based on hospitalized patient data, the majority of COVID19 cases (about $80 \%$ ) presented with asymptomatic or with mild symptoms while the remainder are severe or critical. ${ }^{2,4}$ It seems that the severity and fatality rate of COVID-19 are milder than that of SARS and MERS. With similar clinical presentations as SARS and MERS, the most common symptoms of COVID-19 are fever, fatigue, and respiratory symptoms, including cough, sore throat and shortness of breath. Although diarrhea was presented in about $20-25 \%$ of patients with SARS and MERS, intestinal symptoms were rarely reported in patients with COVID-19. ${ }^{1,24}$ Most patients also developed lymphopenia and pneumonia with characteristic pulmonary ground glass opacity changes on chest CT. ${ }^{1,2,4}$ In addition, the study of 41 hospitalized patients with high-levels of proinflammatory cytokines including IL-2, IL-7, IL-10, G-CSF, IP-10, MCP-1, MIP-1A, and TNFa were observed in the COVID-19 severe cases. ${ }^{2}$ These findings are in line with SARS and MERS in that the presence of lymphopenia and "cytokine storm" may have a major role in the pathogenesis of COVID-19.22-24 This so-called "cytokine storm" can initiate viral sepsis and inflammatory-induced lung injury which lead to other complications including pneumonitis, acute respiratory distress syndrome (ARDS), respiratory failure, shock, organ failure and potentially death. Further autopsy or biopsy studies are necessary to understand more details of this disease.

At present, the mortality rate of COVID-19 worldwide is approximately $2.4 \%$ which are caused by multi-organ failure especially in elderly people and people with underlying health conditions such as hypertension, cardiovascular disease and diabetes.

Innate Immune Responses to SARS-CoV-2 Infection: Gaining Insight from Strategies used by SARS-CoV and MERS-CoV

Currently, only limited information is available on the host innate immune status of SARS-CoV-2 infected patients. In one report where 99 cases in Wuhan were investigated, increased total neutrophils (38\%), reduced total lymphocytes (35\%), 
increased serum IL-6 (52\%) and increased c-reactive protein (84\%) were observed..$^{25}$ In a separate report also from Wuhan, it revealed that in 41 patients, increased total neutrophils, decreased total lymphocytes in patients of ICU vs. non-ICU care were found to be statistically different. Increased neutrophils and decreased lymphocytes also correlate with disease severity and death. ${ }^{1}$ Furthermore, patients needing ICU care had higher plasma levels of many innate cytokines, IP-10, MCP-1, MIP-1A, and TNFa. ${ }^{2}$ These clinical features suggested the likelihood of involvement of highly pro-inflammatory condition in the disease progression and severity. This early high rise in the serum levels of pro-inflammatory cytokines were also observed in SARS-CoV and MERS-CoV infection, suggesting a potential similar cytokine storm-mediated disease severity. ${ }^{23,24}$

Effective innate immune response against viral infection relies heavily on the interferon (IFN) type I responses and its downstream cascade that culminates in controlling viral replication and induction of effective adaptive immune response. While SARS-CoV and SARS-CoV-2 seem to share the entry receptor of ACE2, MERS-CoV uses dipeptidyl peptidase (DPP)-4 as a specific receptor. ${ }^{25}$ The putative receptor of SARS-CoV-2, ACE2, is mainly expressed in a small subset of cells in the lung called type 2 alveolar cells. ${ }^{26}$ It has been reported that SARS-Co-V directly infects macrophages and
T cells, a key feature in SARS-CoV-mediated pathogenesis. ${ }^{27}$ Whether SARS-CoV-2 infects any immune cells are still unknown. Only minimal percentages of monocytes/macrophages in the lung expressed ACE2. ${ }^{26}$ If ACE2 is minimally expressed in the potential target immune cells, it is possible that other receptors may exist, or other cellular entry mode is utilized such as antibody-dependent enhancement (Figure 2).

To mount an antiviral response, innate immune cells need to recognize the invasion of the virus, often by pathogenassociated molecular patterns (PAMPs). For RNA virus such as coronavirus, it is known that PAMPs in the form of viral genomic RNA or the intermediates during viral replication including dsRNA, are recognized by either the endosomal RNA receptors, TLR3 and TLR7 and the cytosolic RNA sensor, RIG-I/ MDA5. This recognition event leads to activation of the downstream signaling cascade, i.e. NF- $\kappa \mathrm{B}$ and IRF3, accompanied by their nuclear translocation. In the nuclei, these transcription factors induce expression of type I IFN and other pro-inflammatory cytokines and this initial responses comprise the first line defense against viral infection at the entry site. ${ }^{28}$ Type I IFN via IFNAR, in turn, activates the JAK-STAT pathway, where JAK1 and TYK2 kinases phosphorylate STAT1 and STAT2. STAT1/2 form a complex with IRF9, and together they move into the nucleus to initiate the transcription of

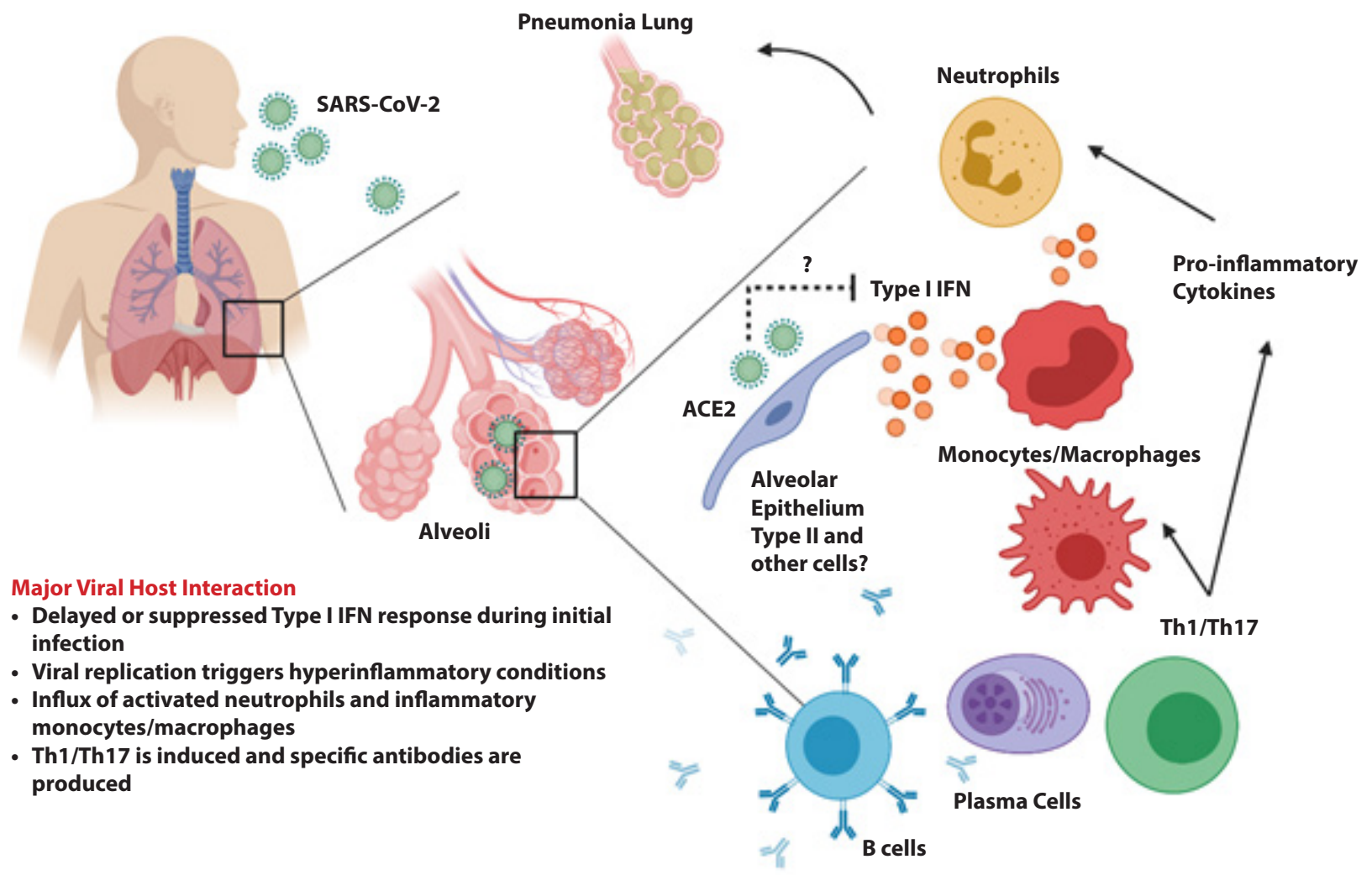

Figure 2. Proposed host immune responses during SARS-CoV-2 infection

Aerosolized uptake of SARS-CoV-2 leads to infection of ACE2 expressing target cells such as alveolar type 2 cells or other unknown target cells. Virus may dampen anti-viral IFN responses resulting in uncontrolled viral replication. The influx of neutrophils and monocytes/macrophages results in hyperproduction of pro-inflammatory cytokines. The immunopathology of lung may be the result of the "cytokine storms". Specific Th1/Th17 may be activated and contributes to exacerbate inflammatory responses. B cells/plasma cells produce SARS-CoV-2 specific antibodies that may help neutralize viruses. The question marks indicated events that are still speculative or unknown. Figure is made with biorender (https://biorender.com/). 
IFN-stimulated genes (ISGs) under the control of IFN-stimulated response element (ISRE) containing promoters. ${ }^{28} \mathrm{~A}$ successful mounting of this type I IFN response should be able to suppress viral replication and dissemination at an early stage.

For SARS-CoV and MERS-CoV, the response to viral infection by type I IFN is suppressed. Both coronaviruses employ multiple strategies to interfere with the signaling leading to type I IFN production and/or the signaling downstream of IFNAR. This dampening strategy is closely associated with the disease severity. ${ }^{29}$ At the step of type I IFN induction, SARS$\mathrm{CoV}$ interferes with the signaling downstream of RNA sensors directly or indirectly such as ubiquitination and degradation of RNA sensor adaptor molecules MAVS and TRAF3/6 and inhibiting IRF3 nuclear translocation. ${ }^{30}$ MERS-CoV also utilizes some of these strategies with additional mechanism such as repressive histone modification. ${ }^{30}$ Once type I IFN is secreted, these two viruses are equipped with mechanism that inhibit IFN signaling such as decreasing STAT1 phosphorylation. ${ }^{28}$ The viral proteins involved in the modulation of this host type I IFN response are both structural proteins (such as $\mathrm{M}, \mathrm{N}$ ) and non-structural proteins (ORF proteins).

Based on the genomic sequence comparison, SARS-CoV shares overall genomic similarity with SARS-CoV or MERS$\mathrm{CoV}$, approximately $79 \%$ and $50 \%$, respectively. The genome of SARS-CoV-2 also contains additional gene regions (10b, 13, 14). In addition, the amino acid sequences of some putative proteins of SARS-CoV-2 show only $68 \%$ similarity with that of SARS-CoV. ${ }^{14}$ Therefore, careful sequence comparison of each gene region may yield better prediction as how SARS-CoV-2 interferes with host innate immune response. It is partially speculative that SARS-CoV-2 utilizes similar strategies to modulate the host innate immune response, especially in dampening the type I IFN response but additional novel mechanisms may be uncovered (Figure 2).

In the severe or lethal cases of SARS-CoV or MERS-CoV infection, increased neutrophil and monocyte-macrophages influx are consistently observed. ${ }^{27,31}$ In a mouse model of SARS$\mathrm{CoV}$ infection, dysregulated type I IFN and inflammatory monocyte-macrophages are the main cause of lethal pneumonia. ${ }^{29}$ Therefore, excessive type I IFN with the infiltrated myeloid cells are the main cause of lung dysfunction and negatively impact the outcome of the infection. It is speculated that upon SARS-CoV or MERS-CoV infection, delayed type I IFN compromises the early viral control, leading to influx of hyperinflammatory neutrophils and monocytes-macrophages. The increases in these innate immune cells yields deteriorating consequences to infected host that manifested in lung immunopathology, including pneumonia or acute respiratory distress syndrome. In SARS-CoV-2 infection, similar scenario is expected with varying degree of immune interference. Interestingly, transmission of virus is reported to occur even in asymptomatic infected individuals. This may be indicative of delayed early response of the innate immune response.

Based on the accumulated data for previous coronavirus infection, innate immune response plays crucial role in protective or destructive responses and may open a window for immune intervention. Active viral replication later results in hyperproduction type I IFN and influx of neutrophils and macrophages which are the major sources of pro-inflammatory cytokines. With similar changes in total neutrophils and lymphocytes during COVID19, SARS-CoV-2 probably induces delayed type I IFN and loss of viral control in an early phase of infection. Individuals susceptible to CoVID19 are those with underlying diseases, including diabetes, hypertension, and cardiovascular disease. ${ }^{2}$ In addition, no severe cases were reported in young children, when innate immune response is highly effective. These facts strongly indicate that innate immune response is a critical factor for disease outcome.

Based on the assumption that innate immunity plays a key role, several interventions can be proposed. Type I IFN, antagonists of some key pro-inflammatory cytokines and anti-viral agents are some of these examples. When using type I IFN for treatment, in a mouse model of either SARS-CoV or MERS$\mathrm{CoV}$ infection, the timing of administration is key to yield protective response. ${ }^{29}$

\section{Adaptive Immune Responses: A Clue for Future Vaccine De- velopment?}

In general, the Th1 type immune response plays a dominant role in an adaptive immunity to viral infections. Cytokine microenvironment generated by antigen presenting cells dictate the direction of T cell responses. Helper T cells orchestrate the overall adaptive response, while cytotoxic $\mathrm{T}$ cells are essential in killing of viral infected cells. Humoral immune response, especially production of neutralizing antibody, plays a protective role by limiting infection at later phase and prevents reinfection in the future. In SARS-CoV, both T and B cell epitopes were extensively mapped for the structural proteins, S, N, M and $\mathrm{E}$ protein. ${ }^{32}$

SARS-CoV infection induces seroconversion as early as day 4 after onset of disease and was found in most patients by 14 days. Long lasting specific IgG and neutralizing antibody are reported as long as 2 years after infection. ${ }^{33}$ For MERS-CoV infection, seroconversion is seen at the second or third week of disease onset. For both types of coronavirus infections, delayed and weak antibody response are associated with severe outcome. $^{32}$ A limited serology details of SARS-CoV-2 was reported. In a preliminary study, one patient showed peak specific IgM at day 9 after disease onset and the switching to IgG by week $2 .^{25}$ Interestingly, sera from 5 patients of confirmed COVID-19 show some cross-reactivity with SARS-CoV, but not other coronavirus. Furthermore, all sera from patients were able to neutralize SARS-CoV-2 in an in vitro plaque assay, suggesting a possible successful mounting of the humoral responses. ${ }^{25}$ Whether the kinetic/titer of specific antibody correlates with disease severity remains to be investigated.

$\mathrm{T}$ cell response in SARS-CoV was extensively investigated. In one study using 128 convalescent samples, it was reported that $\mathrm{CD} 8+\mathrm{T}$ cell responses were more frequent with greater magnitude than CD4+ T cell responses. Furthermore, the virus specific $\mathrm{T}$ cells from the severe group tended to be a central memory phenotype with a significantly higher frequency of polyfunctional CD $4+\mathrm{T}$ cells (IFN $\gamma, \mathrm{TNF}$, and IL-2) and CD8+ T cells (IFN $\gamma, \mathrm{TNF}$ a and degranulated state), as compared with the mild-moderate group. Strong $\mathrm{T}$ cell responses correlated significantly with higher neutralizing antibody while more serum Th2 cytokines (IL-4, IL-5, IL-10) were detected in the fatal group. ${ }^{34}$ For the epitope mapping, most responses 
(70\%) were found against the structural proteins (spike, envelope, membrane, and nucleocapsid). In MERS-CoV infection, early rise of $\mathrm{CD} 8+\mathrm{T}$ cells correlates with disease severity and at the convalescent phase, dominant Th1 type helper $\mathrm{T}$ cells are observed. ${ }^{35}$ In an animal model, airway memory CD4+ T cells specific for conserved epitope are protective against lethal challenge and can cross react with SARS-CoV and MERSCoV. ${ }^{36}$ As neutrophils play a destructive role in all infections, the protective or destructive role of Th17 in human coronavirus infection remains unanswered.

Current evidences strongly indicated that Th1 type response is a key for successful control of SARS-CoV and MERS$\mathrm{CoV}$ and probably true for SARS-CoV-2 as well. CD8+ T cell response, even though crucial, needs to be well controlled in order not to cause lung pathology. Because most epitopes identified for both viruses concentrate on the viral structural proteins, it will be informative to map those epitopes identified with SARS-CoV/MERS-CoV with those of SARS-CoV-2. If overlapping epitopes among the three viruses can be identified, it will be beneficial for application in passive immunization using convalescent serum from recovered SARS or MERS patients. For T cell epitopes, it will help in designing cross reactive vaccine that protect against all three human coronaviruses in the future.

\section{Potential Immune Evasion Mechanisms}

Current observations indicate that coronaviruses are particularly adapted to evade immune detection and dampen human immune responses. This partly explains why they tend to have a longer incubation period, 2-11 days on average compared to influenza, 1-4 days. ${ }^{37}$ The longer incubation period is probably due to their immune evasion properties, efficiently escaping host immune detection at the early stage of infection. As a member of the Betacoronavirus genus, immune evasion mechanism is potentially similar to those of SARS-CoV and MERS-CoV. The mechanisms of how SARS-CoV and MERS$\mathrm{CoV}$ modulate host immune responses were extensively reviewed and discussed (Figure 3). ${ }^{30,38,39}$ In brief, most mechanisms rely on the inhibition of innate immune responses, especially type I interferon recognition and signaling. The viral proteins including membrane $(\mathrm{M})$ or nonstructural (NS) proteins (eg. NS4a, NS4b, NS15) are the key molecules in host immune modulation. In agreement with the aforementioned study, analysis of two MERS-CoV-infected individuals with different severity found that the type I interferon response in the poor outcome (death) patient was remarkably lower than the recovered patient. ${ }^{40}$ For adaptive immune evasion, antigen presentation via MHC class I and MHC class II was downregulated when the macrophages or dendritic cells were infected with MERS-CoV, which would markedly diminish $\mathrm{T}$ cells activation. $^{38}$

\section{Prophylactic Vaccines: Is it possible?}

Due to the rapid increase of SAR-CoV-2 infections and affected countries, efforts toward developing an effective SAR$\mathrm{CoV}-2$ vaccine have been ignited in many countries. By gaining

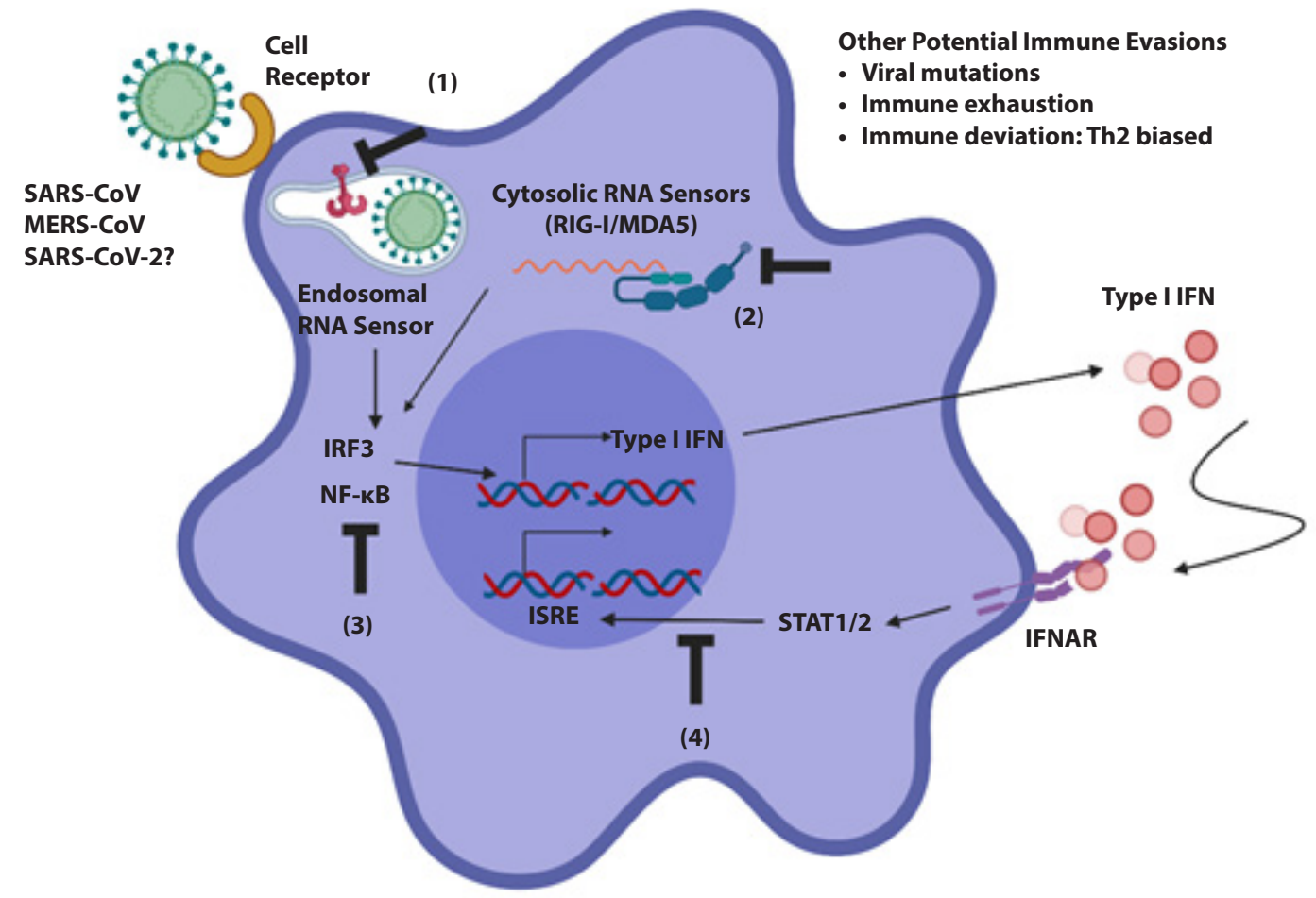

Figure 3. Potential immune evasion mechanisms shared by SARS-CoV, MERS-CoV and SARS-CoV-2.

Coronaviruses interfere with multiple steps during initial innate immune response, including RNA sensing (1 and 2), signaling pathway of type I IFN production (3), STAT1/2 activation downstream of IFN/IFNAR (4) as indicated by suppressive marks. This delayed or dampening type I IFN responses impinge upon adaptive immune activation. Prolonged viral persistence exacerbates inflammatory responses that may lead to immune exhaustion and immune suppression as a feedback regulatory mechanism. Biased Th2 type response also favors poor outcome of the disease. 
Table 2. Selected antigens and vaccine platforms that have been tested for SARS-CoV and MERS-CoV (Modified from ${ }^{50-52}$ )

\begin{tabular}{|c|c|c|c|c|}
\hline Vaccine platform & Immunogen & Phase & Advantage & Disadvantage \\
\hline DNA & $\begin{array}{l}\text { Full-length Spike, or S1 } \\
\text { - IM follow by electroporation }\end{array}$ & $\begin{array}{c}\text { Phase I, II } \\
\text { (NCT03721718) }\end{array}$ & $\begin{array}{l}\text { - Rapid production } \\
\text { - Easy design and manipulation } \\
\text { - Induce both B and T cells } \\
\text { responses }\end{array}$ & $\begin{array}{l}\text { - Efficient delivery system required } \\
\text { - Induce lower immune responses } \\
\text { when compare with live vaccine }\end{array}$ \\
\hline Viral vector & $\begin{array}{l}\text { Full-length Spike or S1 } \\
\text { - Vector used: ChAd or MVA }\end{array}$ & $\begin{array}{l}\text { Phase I } \\
\text { (NCT03399578, } \\
\text { NCT03615911) }\end{array}$ & $\begin{array}{l}\text { - Excellence in immune } \\
\text { induction }\end{array}$ & $\begin{array}{l}\text { - Varies inoculation routes may } \\
\text { produce different immune responses } \\
\text { - Possible TH2 bias }\end{array}$ \\
\hline Subunit & $\begin{array}{l}\text { Full-length Spike, S1, RDB, } \\
\text { nucleocapsid } \\
\text { - Formulated with various } \\
\text { adjuvants and/or fused with } \\
\text { Fc }\end{array}$ & Preclinical & $\begin{array}{l}\text { - High safety profile } \\
\text { - Consistent production } \\
\text { - Can induce cellular and } \\
\text { humoral immune responses }\end{array}$ & $\begin{array}{l}\text { - Need appropriate adjuvant, } \\
\text { - Cost-effectiveness may vary }\end{array}$ \\
\hline Virus-like particles & $\begin{array}{l}\mathrm{RDB}, \mathrm{S} \text { or Co-expressing of } \mathrm{S} 1 \text {, } \\
\mathrm{M} \text {, and } \mathrm{E} \\
\text { - Produced in baculovirus }\end{array}$ & Preclinical & $\begin{array}{l}\text { - Multimeric antigen display } \\
\text { - Preserve virus particle structure }\end{array}$ & - Require optimum assembly condition \\
\hline Inactivated & $\begin{array}{l}\text { Whole virus } \\
\text { - Inactivated by Formaldehyde } \\
\text { or gamma irradiation }\end{array}$ & Preclinical & $\begin{array}{l}\text { - Preserve virus particle structure } \\
\text { - Rapid development } \\
\text { - Excellence in neutralizing Ab } \\
\text { induction } \\
\text { - Can be formulated with various } \\
\text { adjuvant }\end{array}$ & $\begin{array}{l}\text { - Possible cause hypersensitivity } \\
\text { - Possible Th2-bias }\end{array}$ \\
\hline Live-attenuated virus & $\begin{array}{l}\text { Mutant MERS-CoV and } \\
\text { SARS-CoV or recombination } \\
\text { with other live attenuated } \\
\text { virus }\end{array}$ & Preclinical & $\begin{array}{l}\text { - Excellence in induction of } \mathrm{T} \\
\text { and B cells responses } \\
\text { - Site-directed mutagenesis can } \\
\text { be tailor made }\end{array}$ & $\begin{array}{l}\text { - Risk of reversion to a virulent strain } \\
\text { - Cold chain required } \\
\text { - Not suitable or sensitive population } \\
\text { such as infants, immunocompromised } \\
\text { or elderly individuals }\end{array}$ \\
\hline
\end{tabular}

ChAd: Chimpanzee adenovirus vector, MVA: Modified Vaccinia Ankara

knowledge from SARS and MERS vaccines development path, several research groups have been able to start SAR-CoV-2 vaccine development within only a few weeks after the outbreak. The target antigen selection and vaccine platform are probably based on SARS-CoV and MERS-CoV vaccine studies, summarized in Table 2. Full-length spike (S) or S1 which contains receptor binding domain (RDB) might be considered as a good vaccine antigen because it could induce neutralizing antibodies that prevent host cell attachment and infection. ${ }^{41-43}$ Table 2 describes the selected antigens and platforms that have been tested for SARS-CoV and MERS-CoV in clinical and preclinical studies.

Interestingly, as summarized in the Table 2, nucleic acidbased vaccine, DNA vaccine, showed the most advance platform in response to emerging pathogens. Moreover, during Zika virus outbreak, DNA vaccine was the first vaccine candidate that entered clinical trial (NCT02809443) ${ }^{44}$ (less than 1-year after the outbreak). According to the current technological advancement, mRNA vaccine, another nucleic acid-based vaccine, has been considered as disruptive vaccine technology. Recent mRNA vaccine designs have improved stability and protein translation efficiency thus it could induce robust immune responses. ${ }^{45,46}$ Delivery system such as lipid nanoparticle, LNP was also well-optimized. ${ }^{47}$

Within two months of the SAR-CoV-2 outbreak, at least 37 biopharmaceutical companies or academic sectors are in the race to develop the prophylactic vaccine by using several platforms including mRNA, DNA, adenoviral vector and recombinant protein. ${ }^{48}$ In order to make SAR-CoV-2 vaccine possible, gathering of important information for vaccine development and evaluation should be well defined. This includes finding target antigen(s), immunization route, correlated-immune protection, animal models, scalability, production facility, target product profile (TPP), outbreak forecasting and target population. International collaboration as well as technology transfer between experts will also help SARS-CoV-2 vaccine development quickly move forward. Lesson-learned from Zika, in order to speed up the available vaccine during ongoing outbreak, preclinical studies of SAR-CoV-2 vaccine candidates may need to be performed in parallel with clinical trials. However, before entering clinical testing, the regulatory agencies must assess the production process and preclinical information to ensure volunteers' safety. ${ }^{49}$

By looking at the similarities and differences between the current SARS-CoV-2 and the previous outbreak of SARS and MERS, a striking similarity emerges with some unique features of its own. As the COVID-19 causes serious public health concerns across Asia and on the blink to affect world population, investigation into the characteristics of SARS-CoV-2, its interaction with the host immune responses may help provide a clearer picture of how the pathogen causes diseases in some individuals while most infected people only show mild or no symptoms at all. In addition, the study of the immune correlates of protection and the long-term immune memory from convalescent individuals may help in design prophylactic and therapeutic measures for future outbreak of similar coronaviruses. 


\section{Conflict of interest}

The authors declare no conflict of interest

\section{Acknowledgement}

Authors would like to thank Professor Kiat Ruxrungtham for his invaluable scientific inputs and critical reading of the manuscript.

\section{References}

1. Wu F, Zhao S, Yu B, Chen YM, Wang W, Song ZG, et al. A new coronavirus associated with human respiratory disease in China. Nature [Preprint]. 2020 [cited 2020 Feb 16]: [19 p.]. Available from: https://doi.org/10.1038/ s41586-020-2008-3.

2. Huang C, Wang Y, Li X, Ren L, Zhao J, Hu Y, et al. Clinical features of patients infected with 2019 novel coronavirus in Wuhan, China. Lancet. 2020;395:497-506.

3. Cyranoski D. Did pangolins spread the China coronavirus to people [Internet]. Heidelberg: Springer Nature; 2020 [cited 2020 Feb 16]. Available from: https://www.nature.com/articles/d41586-020-00364-2

4. Chan JF, Yuan S, Kok KH, To KK, Chu H, Yang J, et al. A familial cluster of pneumonia associated with the 2019 novel coronavirus indicating person-to-person transmission: a study of a family cluster. Lancet. 2020; 395:514-23.

5. Li Q, Guan X, Wu P, Wang X, Zhou L, Tong Y, et al. Early Transmission Dynamics in Wuhan, China, of Novel Coronavirus-Infected Pneumonia. N Engl J Med [Preprint]. 2020 [cited 2020 Feb 16]: [9 p.]. Available from: https://doi.org/10.1056/NEJMoa2001316

6. Center for Systems Science and Engineering [Internet]. Baltimore: Johns Hopkins; c2020 [cited 2020 Feb 16]. Coronavirus COVID-19 Global Cases by Johns Hopkins CSSE 2020; [about 1 screen]. Available from: https://gisanddata.maps.arcgis.com/apps/opsdashboard/index.html\#/b da7594740fd40299423467b48e9ecf6

7. World Health Organization [Internet]. Geneva; World Health Organization; c2020 [cited 2020 Feb 16]. Summary of probable SARS cases with onset of illness from 1 November 2002 to 31 July 2003; [about 4 screens]. Available from: https://www.who.int/csr/sars/country/table2004 04 21/en/.

8. World Health Organization [Internet]. Geneva; World Health Organization; c2020 [cited 2020 Feb 16]. Middle East respiratory syndrome coronavirus (MERS-CoV) 2019; [about 4 screens]. Available from: https://www.who. int/emergencies/mers-cov/en/.

9. Rothe C, Schunk M, Sothmann P, Bretzel G, Froeschl G, Wallrauch C, et al. Transmission of 2019-nCoV Infection from an Asymptomatic Contact in Germany. N Engl J Med [Preprint]. 2020 [cited 2020 Feb 16]: [2 p.]. Available from: https://www.nejm.org/doi/pdf/10.1056/NEJMc2001468? articleTools $=$ true

10. Fraser C, Riley S, Anderson RM, Ferguson NM. Factors that make an infectious disease outbreak controllable. Proc Natl Acad Sci U S A. 2004; 101:6146-51.

11. Backer JA, Klinkenberg D, Wallinga J. Incubation period of 2019 novel coronavirus (2019-nCoV) infections among travellers from Wuhan, China, 20-28 January 2020. Euro Surveill. 2020;25.

12. Guan W, Ni Z, Hu Y, Liang W, Ou C, He J, et al. Clinical characteristics of 2019 novel coronavirus infection in China. medRxiv [Preprint]. 2020 [cited 2020 Feb 10]: [30 p.]. Available from: http://medrxiv.org/content/ early/2020/02/09/2020.02.06.20020974.abstract

13. World Health Organization holds news conference on coronavirus outbreak - 2/11/2020 [Internet]. New Jersey: CNBC Television; $2020 \mathrm{Feb}$ 11 [cited 2020 Feb 16]. Video:1:12:45 hr. Available from: https://www. youtube.com/watch? $\mathrm{v}=\mathrm{a} 0 \mathrm{Nu} 5 \mathrm{MUR} \&$ feature $=$ youtu.be $\& \mathrm{t}=2166$

14. Lu R, Zhao X, Li J, Niu P, Yang B, Wu H, et al. Genomic characterisation and epidemiology of 2019 novel coronavirus: implications for virus origins and receptor binding. Lancet. 2020;395:565-74.

15. Hoffmann M K-WH, Krüger N, Müller M, Drosten C, Pöhlmann S. The novel coronavirus 2019 (2019-nCoV) uses the SARS-coronavirus receptor ACE2 and the cellular protease TMPRSS2 for entry into target cells. bioRxiv [Preprint]. 2020 [cited $2020 \mathrm{Feb} \mathrm{16}$ ]: [23 p.]. Available from: https://www. biorxiv.org/content/10.1101/2020.01.31.929042v1
16. Wei M, Yuan J, Liu Y, Fu T, Yu X, Zhang ZJ. Novel Coronavirus Infection in Hospitalized Infants Under 1 Year of Age in China. JAMA [Preprint]. 2020 [cited 2020 Feb 16]:[2 p.]. Available from: https://jamanetwork.com/ journals/jama/fullarticle/2761659

17. The Novel Coronavirus Pneumonia Emergency Response Epidemiology Team. Vital Surveillances: The Epidemiological Characteristics of an Outbreak of 2019 Novel Coronavirus Diseases (COVID-19) - China, 2020. China CDC Weekly. 2020;2:113-22.

18. Wu JT, Leung K, Leung GM. Nowcasting and forecasting the potential domestic and international spread of the 2019-nCoV outbreak originating in Wuhan, China: a modelling study. Lancet [Preprint]. 2020 [cited 2020 Feb 15]: [9 p.]. Available from: https://doi.org/10.1016/S0 140-6736(20)30260-9

19. Thompson R. Pandemic potential of 2019-nCoV. Lancet Infect Dis [Preprint]. 2020 [cited 2020 Feb 15]: [1 p.]. Available from: https://doi. org/10.1016/S1473-3099(20)30068-2

20. Center for Disease Control and Prevention [Internet]. Atlanta: CDC; c2020 [cited 2020 Feb 10]. Symptoms of Novel Coronavirus (2019-nCoV); [about 1 screen]. Available from: https://www.cdc.gov/coronavirus/2019-ncov/ about/symptoms.html

21. Chen N, Zhou M, Dong X, Qu J, Gong F, Han Y, et al. Epidemiological and clinical characteristics of 99 cases of 2019 novel coronavirus pneumonia in Wuhan, China: a descriptive study. Lancet. 2020;395:507-13.

22. Nicholls JM, Poon LL, Lee KC, Ng WF, Lai ST, Leung CY, et al Lung pathology of fatal severe acute respiratory syndrome. Lancet. 2003; 361:1773-8.

23. Mahallawi WH, Khabour OF, Zhang Q, Makhdoum HM, Suliman BA MERS-CoV infection in humans is associated with a pro-inflammatory Th1 and Th17 cytokine profile. Cytokine. 2018;104:8-13.

24. Wong CK, Lam CW, Wu AK, Ip WK, Lee NL, Chan IH, et al. Plasma inflammatory cytokines and chemokines in severe acute respiratory syndrome. Clin Exp Immunol. 2004;136:95-103.

25. Zhou P, Yang XL, Wang XG, Hu B, Zhang L, Zhang W, et al. A pneumonia outbreak associated with a new coronavirus of probable bat origin. Nature [Preprint]. 2020 [cited 2020 Feb 15]: [15 p.]. Available from: https://doi. org/10.1038/s41586-020-2012-7

26. Zhu N, Zhang D, Wang W, Li X, Yang B, Song J, et al. A Novel Coronavirus from Patients with Pneumonia in China, 2019. N Engl J Med. 2020; 382:727-33.

27. Perlman S, Dandekar AA. Immunopathogenesis of coronavirus infections implications for SARS. Nat Rev Immunol. 2005;5(12):917-27.

28. de Wit E, van Doremalen N, Falzarano D, Munster VJ. SARS and MERS: recent insights into emerging coronaviruses. Nat Rev Microbiol. 2016;14: 523-34.

29. Channappanavar R, Perlman S. Pathogenic human coronavirus infections: causes and consequences of cytokine storm and immunopathology. Semin Immunopathol. 2017;39:529-39.

30. Kindler E, Thiel V, Weber F. Interaction of SARS and MERS Coronaviruses with the Antiviral Interferon Response. Adv Virus Res. 2016;96:219-43.

31. Zumla A, Hui DS, Perlman S. Middle East respiratory syndrome. Lancet. 2015;386:995-1007.

32. Liu WJ, Zhao M, Liu K, Xu K, Wong G, Tan W, et al. T-cell immunity of SARS-CoV: Implications for vaccine development against MERS-CoV. Antiviral Res. 2017;137:82-92.

33. Liu W, Fontanet A, Zhang PH, Zhan L, Xin ZT, Baril L, et al. Two-year prospective study of the humoral immune response of patients with severe acute respiratory syndrome. J Infect Dis. 2006;193:792-5.

34. Li CK, Wu H, Yan H, Ma S, Wang L, Zhang M, et al. T cell responses to whole SARS coronavirus in humans. J Immunol. 2008;181:5490-500.

35. Shin HS, Kim Y, Kim G, Lee JY, Jeong I, Joh JS, et al. Immune Responses to Middle East Respiratory Syndrome Coronavirus During the Acute and Convalescent Phases of Human Infection. Clin Infect Dis. 2019;68: 984-92.

36. Zhao J, Zhao J, Mangalam AK, Channappanavar R, Fett C, Meyerholz DK, et al. Airway Memory CD4(+) T Cells Mediate Protective Immunity against Emerging Respiratory Coronaviruses. Immunity. 2016;44:1379-91.

37. Lessler J, Reich NG, Brookmeyer R, Perl TM, Nelson KE, Cummings DA. Incubation periods of acute respiratory viral infections: a systematic review. Lancet Infect Dis. 2009;9:291-300.

38. Shokri S, Mahmoudvand S, Taherkhani R, Farshadpour F. Modulation of the immune response by Middle East respiratory syndrome coronavirus. J Cell Physiol. 2019;234:2143-51. 
39. Kikkert M. Innate Immune Evasion by Human Respiratory RNA Viruses. J Innate Immun. 2020;12:4-20.

40. Faure E, Poissy J, Goffard A, Fournier C, Kipnis E, Titecat M, et al. Distinct immune response in two MERS-CoV-infected patients: can we go from bench to bedside? PLoS One. 2014;9:e88716.

41. Al-Amri SS, Abbas AT, Siddiq LA, Alghamdi A, Sanki MA, Al-Muhanna MK, et al. Immunogenicity of Candidate MERS-CoV DNA Vaccines Based on the Spike Protein. Sci Rep. 2017;7:44875.

42. Du L, He Y, Zhou Y, Liu S, Zheng BJ, Jiang S. The spike protein of SARS-CoV--a target for vaccine and therapeutic development. Nat Rev Microbiol. 2009;7:226-36.

43. Du L, Zhao G, He Y, Guo Y, Zheng BJ, Jiang S, et al. Receptor-binding domain of SARS-CoV spike protein induces long-term protective immunity in an animal model. Vaccine. 2007;25:2832-8.

44. Tebas P, Roberts CC, Muthumani K, Reuschel EL, Kudchodkar SB, Zaidi FI, et al. Safety and Immunogenicity of an Anti-Zika Virus DNA Vaccine Preliminary Report. N Engl J Med [Preprint]. 2017[cited 2020 Feb 10]:[16 p.]. Available from: https://doi.org/10.1056/ NEJMoa1708120
45. Pardi N, Hogan MJ, Porter FW, Weissman D. mRNA vaccines - a new era in vaccinology. Nat Rev Drug Discov. 2018;17:261-79.

46. Maruggi G, Zhang C, Li J, Ulmer JB, Yu D. mRNA as a Transformative Technology for Vaccine Development to Control Infectious Diseases. Mol Ther. 2019;27:757-72

47. Reichmuth AM, Oberli MA, Jaklenec A, Langer R, Blankschtein D. mRNA vaccine delivery using lipid nanoparticles. Ther Deliv. 2016;7:319-34.

48. Koch S, Pong W, Editors. The count of companies developing vaccines for coronavirus rises 2020 [Internet]. Redwood: BioCentury; 2020 [cited 2020 Feb 16]. Available from: https://www.biocentury.com/article/304412

49. Thomas SJ, L'Azou M, Barrett AD, Jackson NA. Fast-Track Zika Vaccine Development - Is It Possible? N Engl J Med. 2016;375:1212-6.

50. Song Z, Xu Y, Bao L, Zhang L, Yu P, Qu Y, et al. From SARS to MERS, Thrusting Coronaviruses into the Spotlight. Viruses. 2019;11.

51. Yong CY, Ong HK, Yeap SK, Ho KL, Tan WS. Recent Advances in the Vaccine Development Against Middle East Respiratory Syndrome -Coronavirus. Front Microbiol. 2019;10:1781.

52. Schindewolf C, Menachery VD. Middle East Respiratory Syndrome Vaccine Candidates: Cautious Optimism. Viruses. 2019;11. 